\title{
Supporting Information: Phase Separation of Aqueous Poly(diisopropylaminoethyl methacrylate) upon Heating
}

Linda Salminen $^{\mathrm{a}}$, Erno Karjalainen ${ }^{\mathrm{b} *}$, Vladimir Aseyeva*, Heikki Tenhu ${ }^{\mathrm{a}}$

${ }^{a}$ Department of Chemistry, University of Helsinki, P.O. Box 55 (A.I. Virtasen aukio 1), FIN-00014 HY Helsinki, Finland

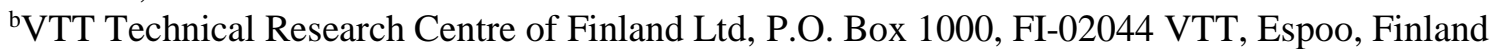

* corresponding authors, E-mail: erno.karjalainen@alumni.helsinki.fi (E.K.) and

vladimir.aseyev@helsinki.fi (V.A.).

A.

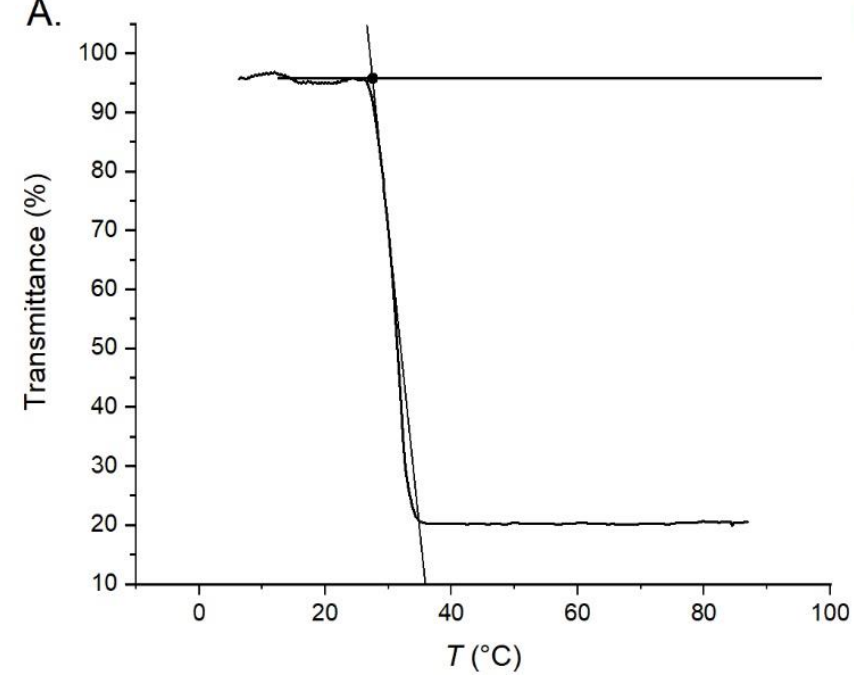

B.

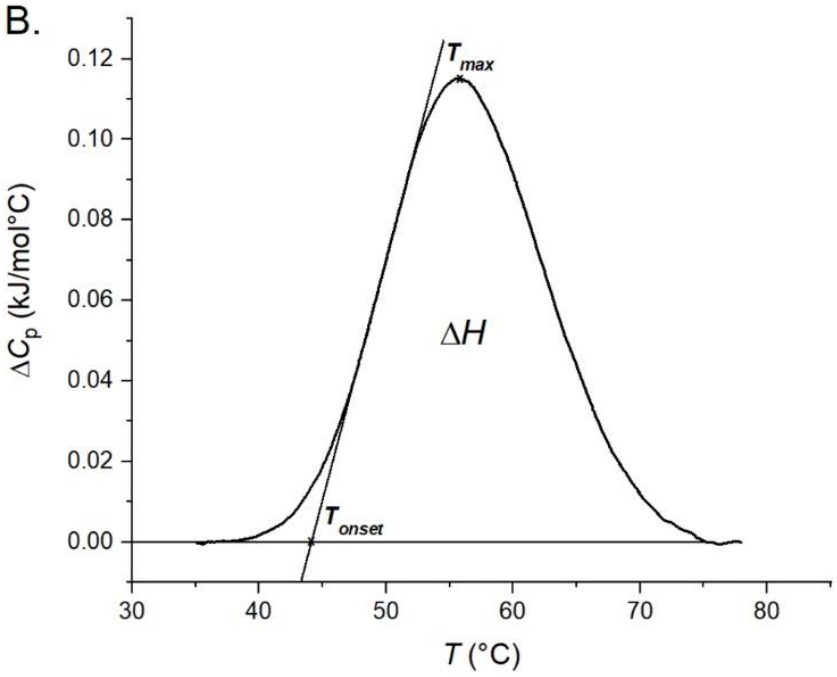

Figure S1. Illustrations of the definitions used in this study: A. Cloud points and clearing points are determined as the intersection of two tangents. B. Microcalorimetric endotherm, where $\Delta H$ is the area under the curve and $T_{\max }$ the peak value. $T_{\text {onset }}$ is determined as the intersection of the two tangents. 
A.

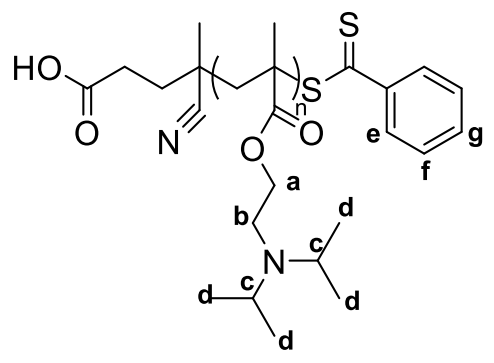

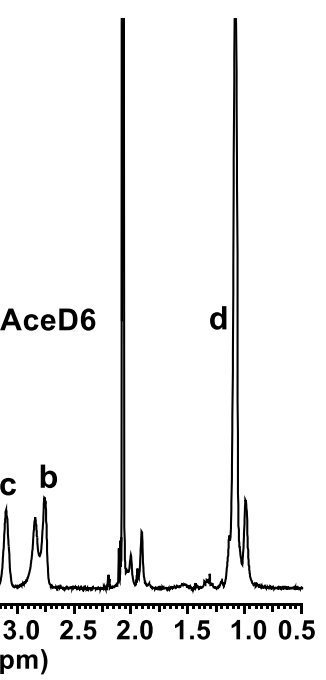

B.

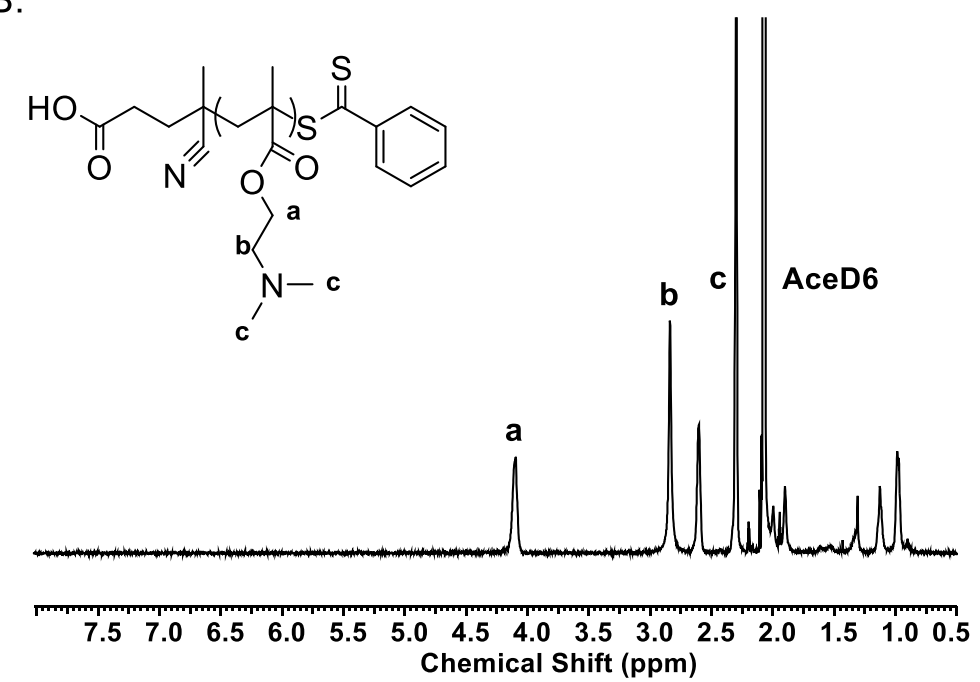
$\begin{array}{lll}5.0 & 4.5 & 4.0 \\ \text { Chemical Shift (ppm) }\end{array}$

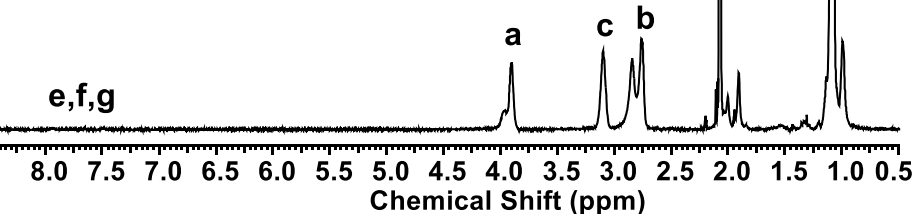

C.

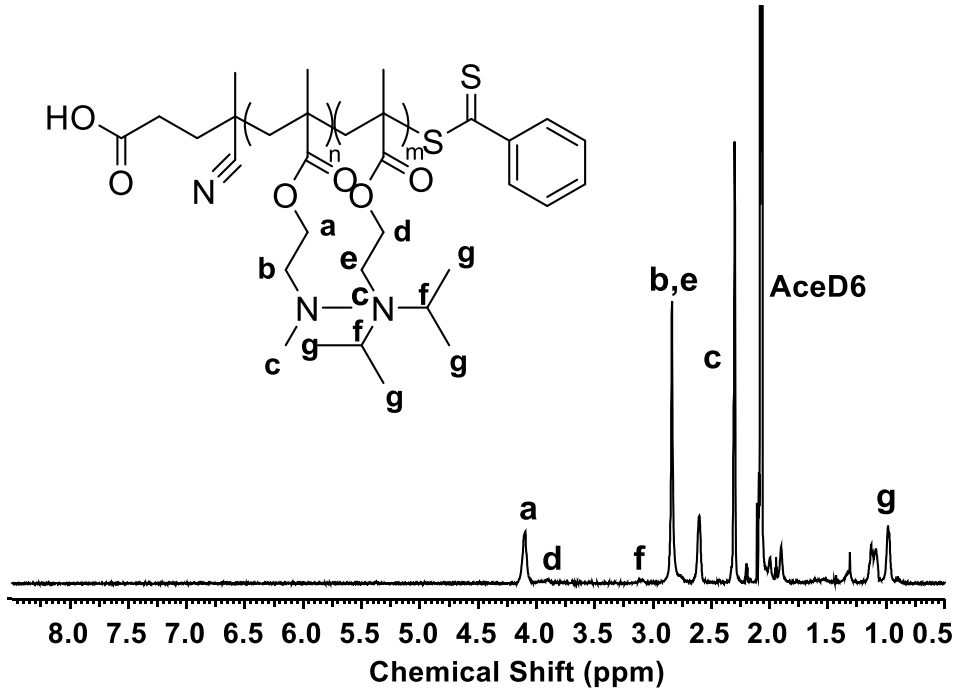

Figure S2. NMR-spectra of A. PDPA, B. PDMAEMA, and C. PDMAEMA- $b$-PDPA. All of the spectra were measured in deuterated acetone (AceD6). 


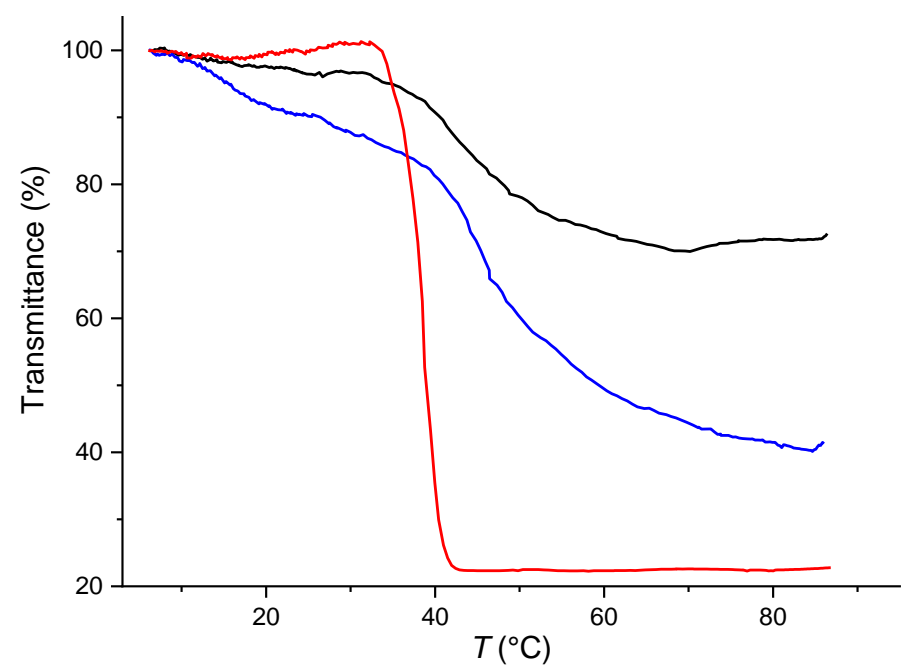

Figure S3. Comparison of transmittance curves of PDPA with different salts. Red: $20 \mathrm{mM}$ citrate, $\mathrm{pH}$ 6.0; Blue: $20 \mathrm{mM}$ phosphate, $\mathrm{pH}$ 6.0, and Black: $250 \mathrm{mM} \mathrm{NaCl}$, pH 5.9.

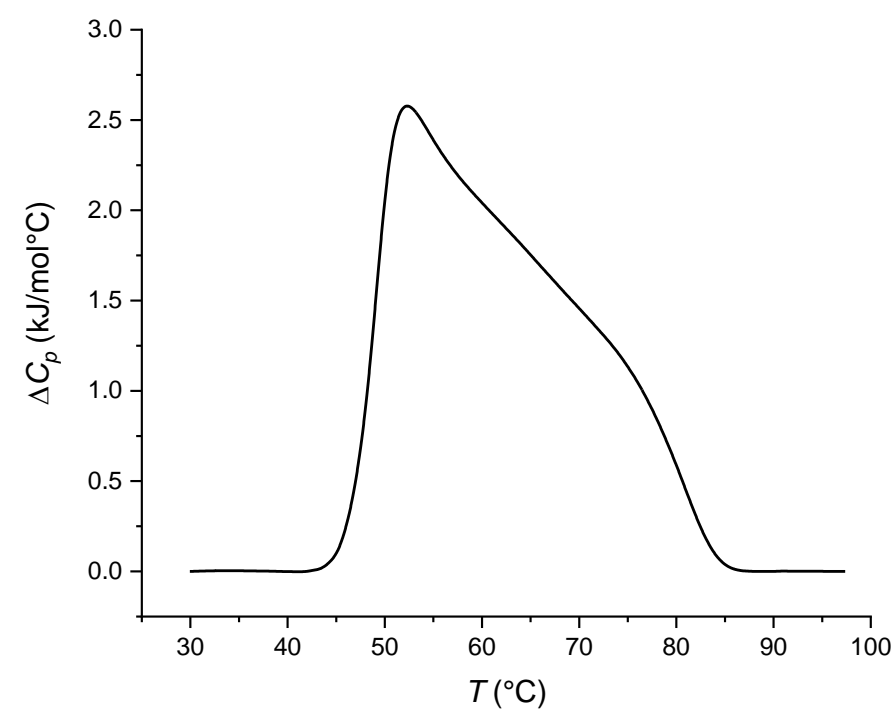

Figure S4. A thermogram of PDPA with $20 \mathrm{mM}$ citrate, $\mathrm{pH}$ 5.6. The enthalpy value is normalised to the concentration of DPA repeating units. 


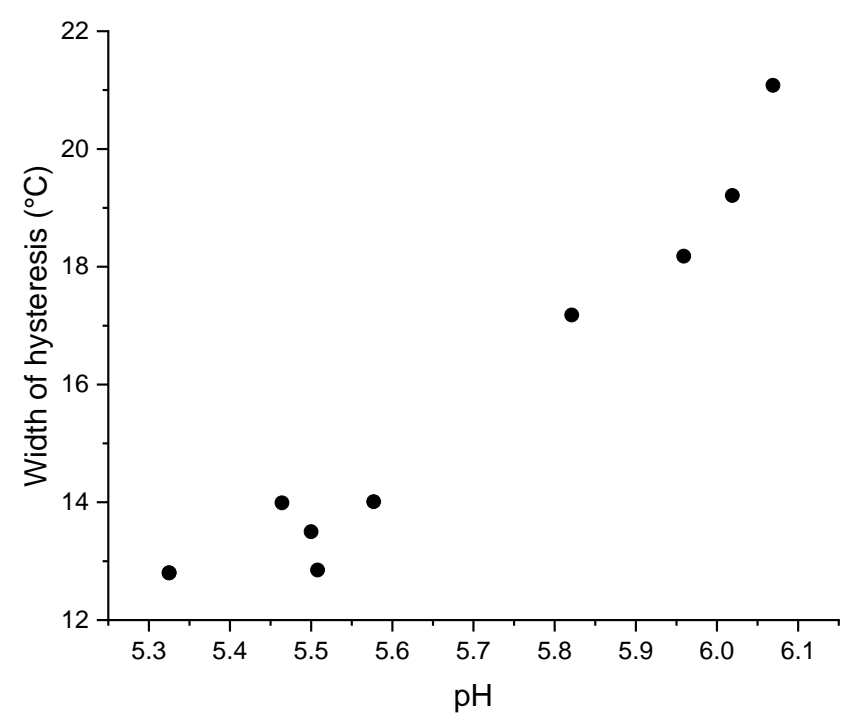

Figure S5. Width of hysteresis of phosphate buffered PDPA as a function of $\mathrm{pH}$. The width of hysteresis was defined as the temperature-difference between the cloud point $\left(T_{c}\right)$ and the clearing point of transmittance measurements.

\section{A. $\mathrm{pH} 5.6$}
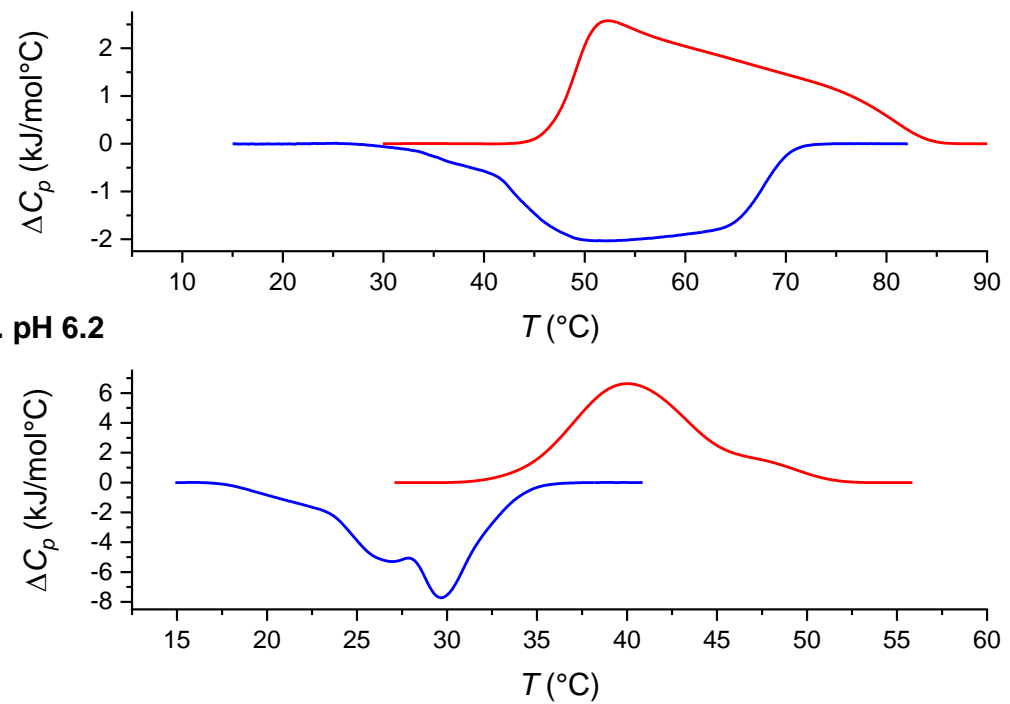

Figure S6. Thermograms of PDPA in $20 \mathrm{mM}$ citrate at $\mathrm{pH} 5.6$ (A), and at $\mathrm{pH} 6.2$ (B). The heating runs have been depicted with red lines and cooling runs with blue lines. 


\section{A. $\mathrm{pH} 5.8$}

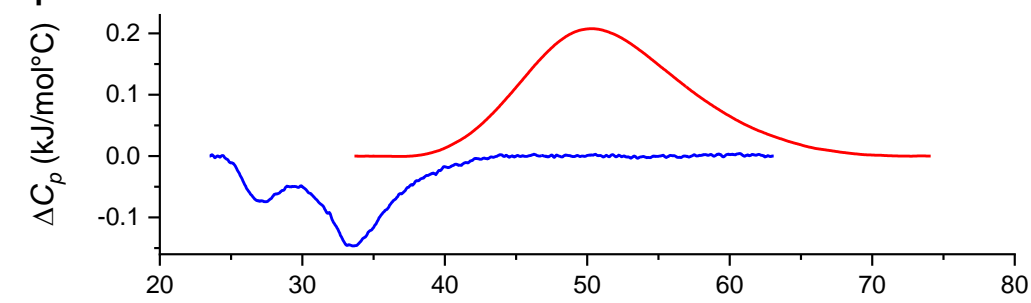

B. $\mathrm{pH} 6.0$

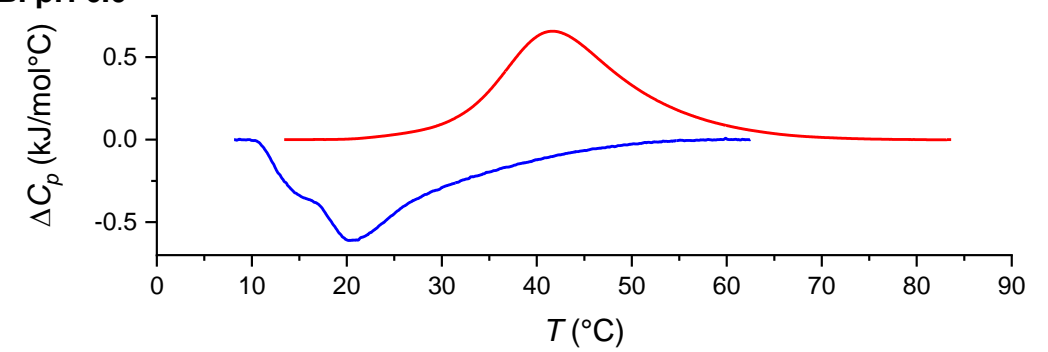

Figure S7. Thermograms of PDPA in $20 \mathrm{mM}$ phosphate at $\mathrm{pH} 5.8$ (A) and at $\mathrm{pH} 6.0$ (B). The heating runs have been depicted in red and cooling runs in blue.

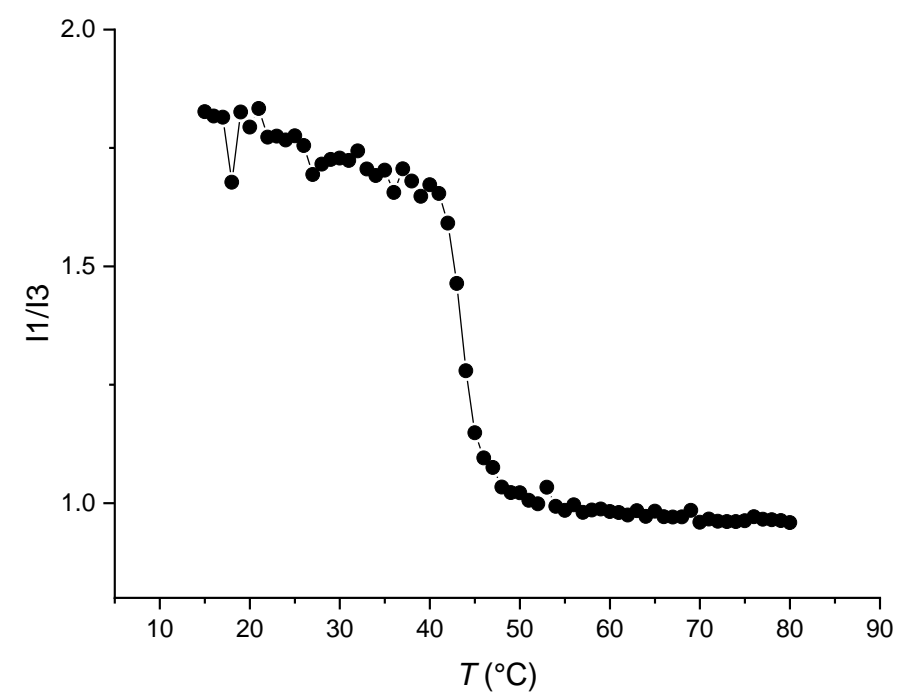

Figure S8. I1/I3 of citrate buffered PDPA ( $\mathrm{pH}$ 5.7) as a function of temperature. The line is a guide to the eye. 


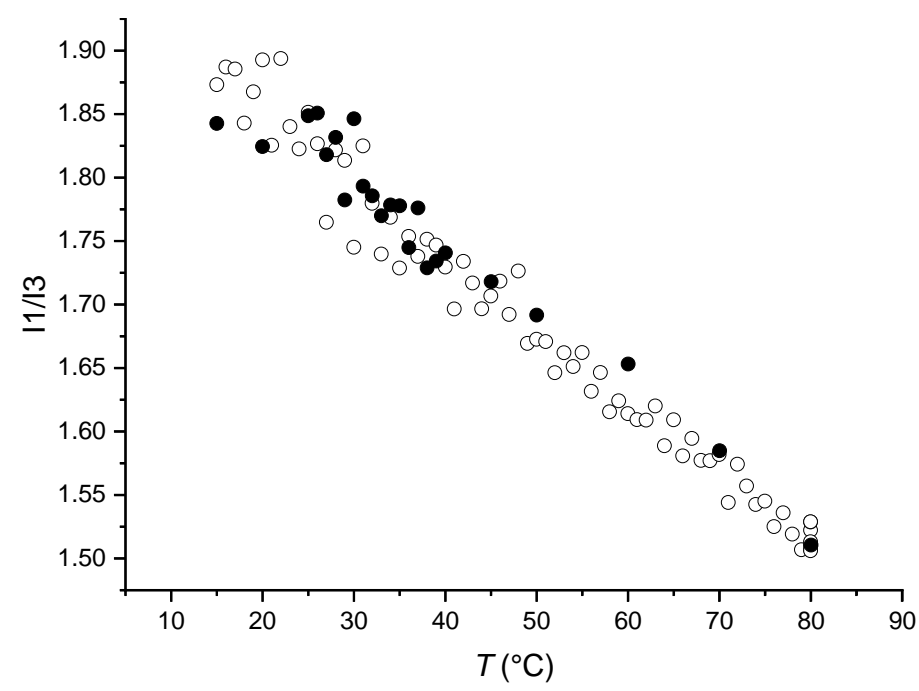

Figure S9. The I1/I3 as a function of temperature for a solution of PDPA with $250 \mathrm{mM} \mathrm{NaCl}$ at pH $5.6(\circ)$ and for an aqueous solution of pyrene without any polymer $(\bullet)$.

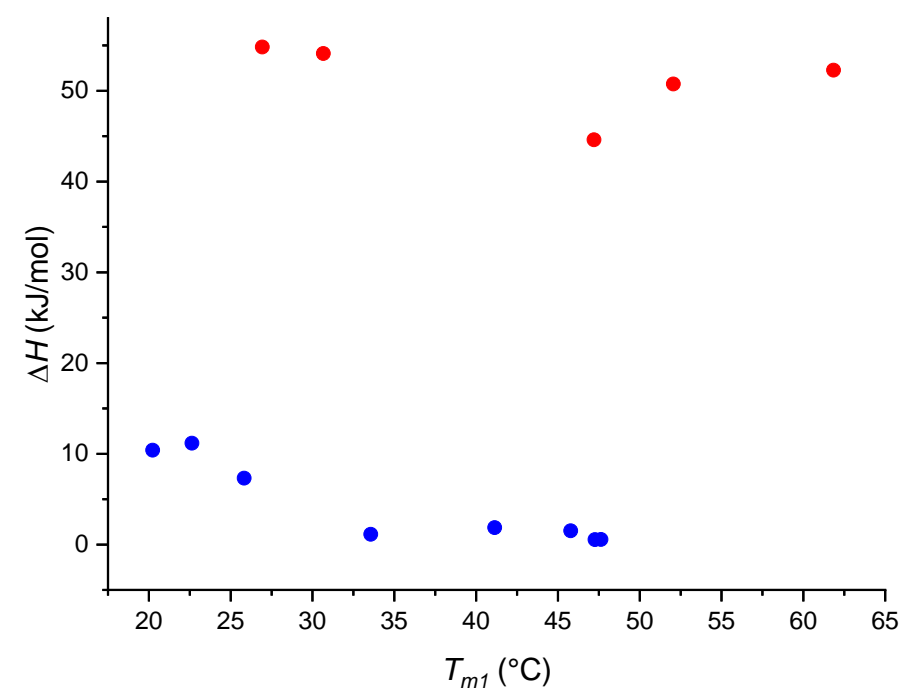

Figure S10. The enthalpy change $(\Delta H)$ of the aggregate dissolution as a function of $T_{m l}$ in citrate (red) and phosphate (blue). The enthalpy values are normalised to the concentration of DPA repeating units. 


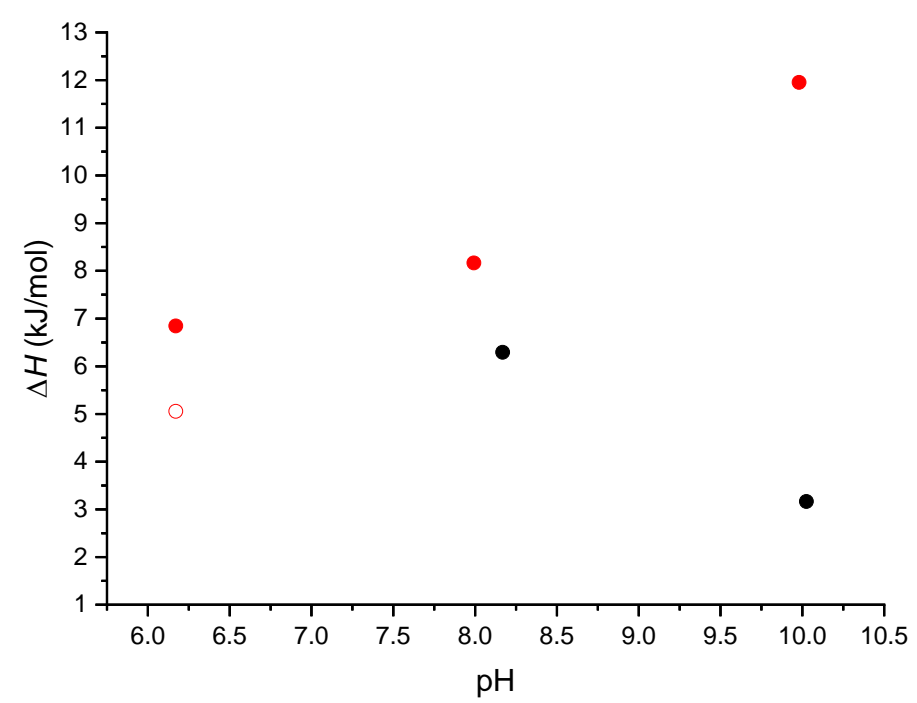

Figure S11. The enthalpy changes of the phase transitions of PDMAEMA- $b$-PDPA (red) and PDMAEMA (black) normalised to the molar concentrations of repeating units. The pH 6 sample of the block copolymer has been normalised to the concentration of PDPA and the pH 8 and 10 samples have been normalised to the concentration of repeating units of PDMAEMA. To facilitate comparison, the block copolymer was also normalised to PDMAEMA (empty symbol).

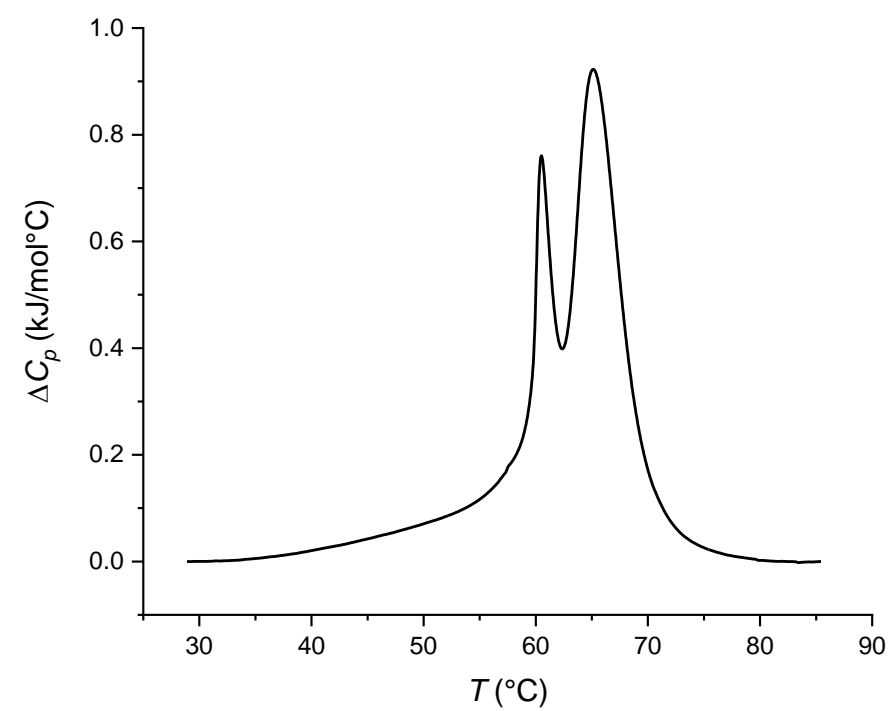

Figure S12. Thermogram of phosphate-buffered PDMAEMA- $b$-PDPA at $\mathrm{pH}$ 8.0. The enthalpy is normalised to the concentration of DMAEMA repeating units. 


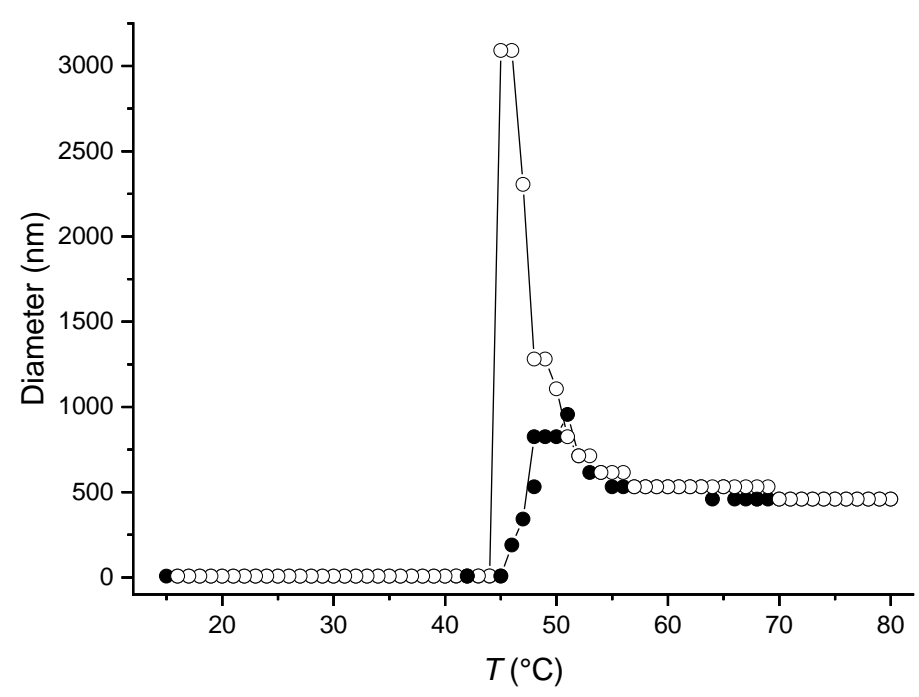

Figure S13. The intensity-average diameter of PDPA particles in the presence of $20 \mathrm{mM}$ citrate as a function of temperature. Heating run (filled symbol) and the cooling run (empty symbol). pH of the solution was 5.6.

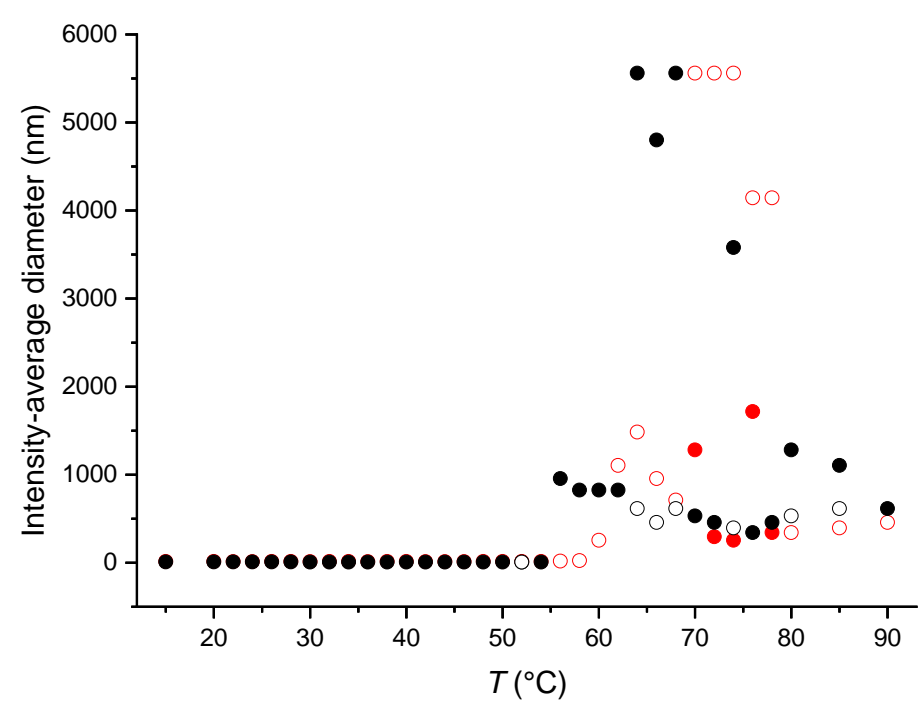

Figure S14. The apparent intensity-average diameters of PDMAEMA homopolymer (black) at $\mathrm{pH} 8.2$ and PDMAEMA- $b$-PDPA (red) at $\mathrm{pH} 8.0$ as a function of temperature. At some temperatures, the size distributions had two maxima, which have both been depicted - one with an empty symbol and one with a filled symbol. 


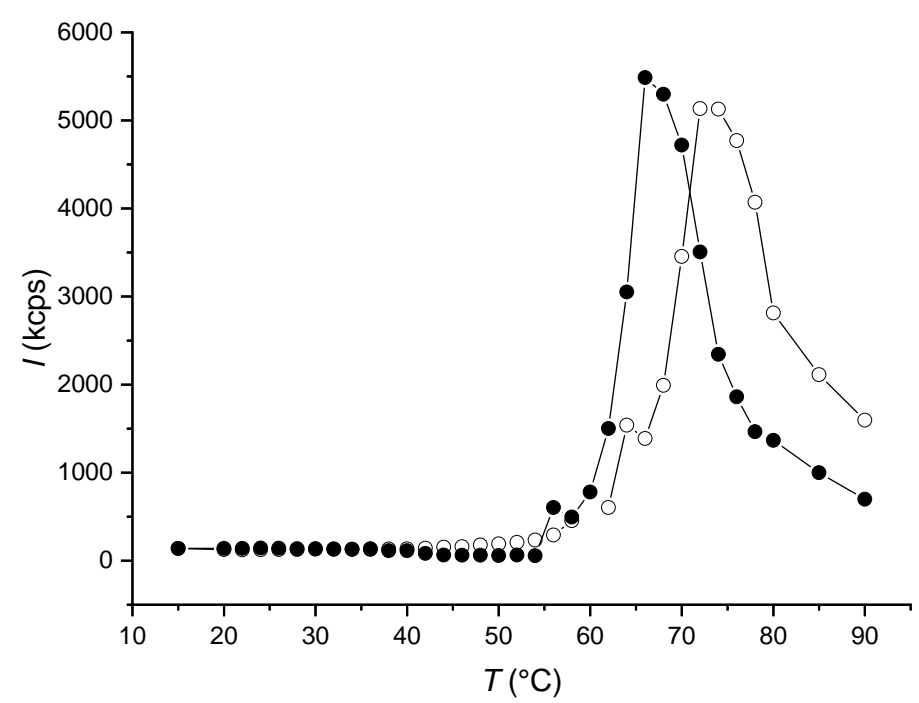

Figure S15. The scattering intensities of PDMAEMA (•) at $\mathrm{pH} 8.2$ and PDMAEMA- $b$-PDPA (०) at $\mathrm{pH}$ 8.0.

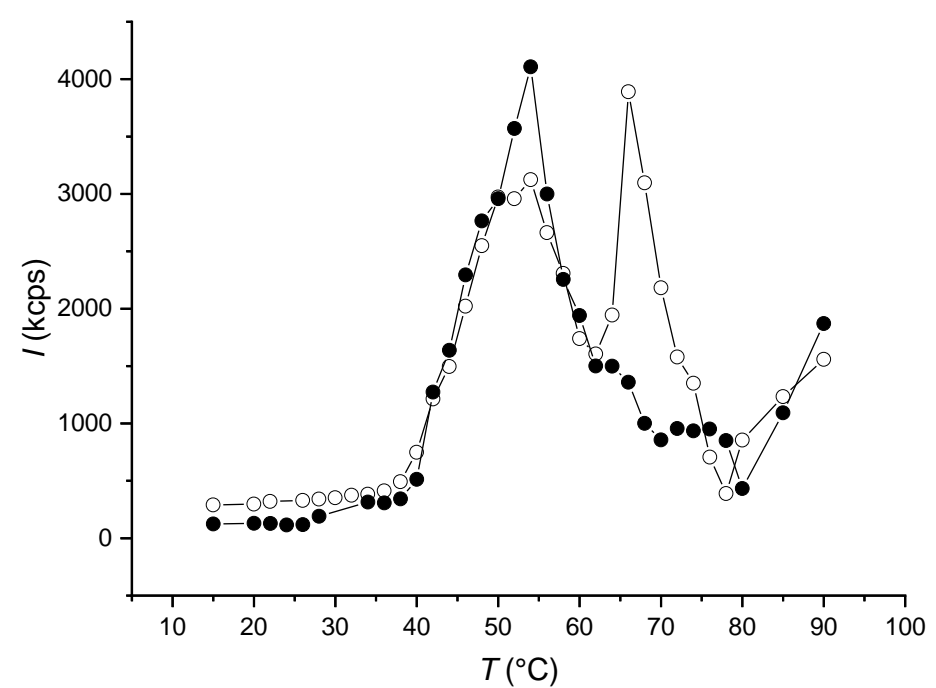

Figure S16. The scattering intensities of PDMAEMA (•) at $\mathrm{pH} 10.0$ and PDMAEMA- $b$-PDPA (०) at pH 9.9. The lines are a guide for the eye. 